\title{
EL MISTERIO RUPESTRE
}

\author{
ANTONIO GONZÁLEZ \\ Fundación Xavier Zibiri (Madrid)
}

\begin{abstract}
RESUMEN: La determinación del significado filosófico de la «religión» es una tarea compleja, que debe considerar lo histórico, lo descriptivo y lo crítico, tratando de abarcar los distintos elementos implicados en un concepto tan saturado de matices. El examen de algunas manifestaciones prehistóricas, como las pinturas rupestres, cuyo sentido determinado posiblemente se nos escape para siempre, puede servir paradójicamente como vía de acceso a algunos elementos constitutivos de lo religioso, precisamente situados más allá de su concreción cultural.
\end{abstract}

PALABRAS CLAVE: religión; fenomenología; Otto; Husserl; Heidegger; Levinas; Henry; Zubiri; sagrado; belleza.

\section{The mystery of the cave paintings}

ABSTRACT: The determination of the philosophical meaning of «religion» is a complex task, which must consider several historical, descriptive and critical dimensions of such a rich concept. The examination of some prehistoric manifestations, like the cave paintings, whose culturally-determined meaning may possibly escape us forever, can paradoxically open a certain access to some constitutive elements of religion, which somehow transcend their cultural concretion.

KEY WORDS: religion; phenomenology; Otto; Husserl; Heidegger; Levinas; Henry; Zubiri; sagrado; belleza.

La determinación de lo que sea la «religión» no es una tarea precisamente fácil. Los diccionarios modernos suelen entender por religión algo así como un «conjunto de creencias relativas a la divinidad» ${ }^{1}$. Sin embargo esta aproximación resulta enormemente problemática.

\section{1. ¿RELIGIÓN?}

La idea de la religión como un «sistema de creencias» difícilmente la encontraremos en el pensamiento antiguo. Ni los hebreos, ni los griegos, tuvieron un concepto que pudiéramos considerar como equivalente a esta moderna idea de lo religioso. El mismo término latino religio no designaba un sistema de creencias, sino que se refería, para decirlo con la famosa expresión de Cicerón, al cultus deorum, al culto a los dioses². De ahí que la religión pudiera ser entendida por este filósofo precisamente en virtud del relegere, es decir, de la cuidadosa atención a los comportamientos debidos a la divinidad ${ }^{3}$.

1 La primera acepción de «religión» en el diccionario de la Real Academia comienza aludiendo al «conjunto de creencias o dogmas acerca de la divinidad».

2 Cf. CicERón, De natura deorum II, 8.

3 Cf $i$ bid. II, 28, 72 
Si la religión es el culto a los dioses, no debería de extrañarnos mucho que de ese concepto quedaran excluidos los primitivos cristianos, cuyas prácticas carecían de los elementos propios de un culto, como serían los comportamientos ritualizados, los espacios sagrados, o el sacerdocio. También carecían propiamente de «dioses», si por tales se entendían algún tipo de entidades pertenecientes a la natura ${ }^{4}$, y por tanto susceptibles de ser ubicadas en los santuarios o en los templos. Más que como religio, el cristianismo primitivo era entendido como un mera superstitio, inconveniente y peligrosa para el imperio ${ }^{5}$. Por eso no es extraño que, siglos más tarde, cuando el cristianismo se alió con Roma, algunos cristianos trataran de transformar el concepto de lo religioso, apelando a una etimología distinta de la de Cicerón. La religión no se definiría primeramente por la atención meticulosa (relegere) a los comportamientos rituales, sino más bien por la «religación» (religare) a la divinidad 6 .

De este modo, la idea de lo religioso ciertamente lograba una cierta independencia del culto externo, al mismo tiempo que el cristianismo comenzaba a ser considerado como «religión». Una religión que inicialmente no estaría caracterizada por el culto, sino por la «virtud» de «religarse» correctamente con la divinidad, dándole lo que ella merece. La idea de la religión como virtud recorre toda la Edad Media y el Renacimiento. En este contexto es comprensible que el término «religión» también comenzara a usarse para designar aquellas formas de vida que los medievales consideraban como las más propiamente «religiosas», por posibilitar el ejercicio de tal virtud. Las «religiones» serían precisamente las «órdenes religiosas». En cambio, aquella pluralidad que nosotros consideraríamos hoy como distintas «religiones» fue designada en la Edad Media y en el Renacimiento con conceptos tales como el de «secta» o «ley» (secta, lex), normalmente usados para expresar su diferencia respecto al cristianismo. Más adelante, cuando los humanistas y los reformadores hablaron de la "religión cristiana», estaban comenzando a usar el término como un concepto genérico, que inicialmente se refería a todo lo relativo al cristianismo. Tras la división de Europa en diversas iglesias territoriales, los autores protestantes comenzaron a usar el término "religión», no ya para designar a las distintas órdenes religiosas, sino para referirse a las diversas «confesiones» cristianas. Solamente con la modernidad nos encontramos la idea de la «religión» como un género con distintas especies subordinadas, que serían las distintas religiones de la humanidad, siendo la cristiana una de ellas ${ }^{7}$.

\footnotetext{
4 Ya Píndaro hablaba de los hombres y los dioses respirando de una misma madre... (cf. Nemea VI, 1, 1-2).

5 Resulta significativo que, incluso en los primitivos escritos cristianos, el esquema mental con el que los competidores trataban de entender al nuevo grupo eran los movimientos revolucionarios, cf. Hch 5:33-42; 17:5-9.

6 Cf. Lactancio, Institutiones Divinae, IV, 28

7 Cf. Sмiтн, W. C., The Meaning and End of Religion, Macmillan, New York, 1964; Feil, E., Religio. Die Geschichte eines neuzeitlichen Grundbegriffs vom Frühchristentum bis zur Reformation, Vandenhoeck \& Ruprecht, Göttingen, 1986.
} 
Este desarrollo, que permite por ejemplo hablar de una «historia de las religiones», mantiene todavía abierta la cuestión decisiva sobre qué sea lo religioso. Si la religión se define como un «sistema de creencias» relativas a la divinidad, podríamos preguntarnos qué es lo que sucede cuando estas creencias no están estructuradas en una forma sistemática, y admiten interminables variaciones, como de hecho sucede en muchas «religiones». Si la religión consistiera primeramente en creencias, cabría preguntarse qué es lo que sucede con aquellas «religiones» en las que las creencias ocupan un lugar más bien secundario, como sucede por ejemplo en el judaísmo. Es bien sabido, que para ser judío no es necesario suscribir un credo, sino más bien cumplir la Torah. Por otra parte, si lo que hace que ciertas creencias sean «religiosas» es su referencia a la divinidad, se plantea la pregunta por lo que sucede con aquellas «religiones» en las que se puede prescindir de los dioses, como es el caso del budismo.

Por supuesto, cabría volver a pensar que las creencias no son lo que define propiamente a la religión. Pero entonces, ¿cuál es la esencia de lo religioso? Si se quiere evitar una pura reducción «ilustrada» de la religión a moralidad, se podría apelar al área de los sentimientos, como hicieron muchos después de Kant. Sin embargo, esto no es una respuesta a nuestra pregunta, sino solamente su aplazamiento, porque entonces hay que determinar qué hace religiosos a los sentimientos. La «dependencia absoluta» de Scheleiermacher tal vez fuera una propuesta demasiado metafísica como para abarcar a todas las religiones positivas. Aquí es donde se fue abriendo paso, en la reflexión contemporánea, el intento de pensar lo religioso a partir de la sacralidad. La experiencia de lo sagrado sería entonces la que definiría la religión. De este modo sería posible englobar en lo religioso tanto a religiones carentes de un sistema de creencias claramente definido, como también a religiones sin alusiones explícitas a la divinidad ${ }^{8}$.

\section{LA SACRALIDAD}

El estudio de la religión a partir de lo sagrado fue desarrollado por una cierta «fenomenología» de la religión, que a veces se denomina «hierológica». Se trata de un enfoque que, durante cierto tiempo, hizo fortuna, y dio lugar a investigaciones sobre la religión enormemente fructíferas. Se trataba de estudiar la religión, no desde fuera de la misma, sino a partir de la experiencia misma del sujeto religioso.

Este modo de proceder tiene sin duda algunas ventajas respecto a las «teorías» usuales sobre la religión. En la teoría se recurre a algún factor concreto, a veces meramente postulado, desde el que se podría explicar la génesis de las experiencias religiosas. Así, por ejemplo, se puede decir que religión se origina

8 Cf. Otto, R., Das Heilige-Über das Irrationale in der Idee des Göttlichen und sein Verhältnis zum Rationalen, C.H. Beck, München, 1963 (Lo santo, Alianza Editorial, Madrid, 1980). 
como una proyección de la propia esencia humana fuera de uno mismo ${ }^{9}$. Una proyección que acaso tendría su origen en la división de la sociedad en clases y en la consiguiente necesidad de un consuelo para los oprimidos ${ }^{10}$. Igualmente, ante la evidencia abrumadora de la existencia de elementos aparentemente «religiosos» antes de la aparición de las clases sociales, se podría tratar de explicar el origen de la religiosidad recurriendo al encuentro de los humanos con otros seres vivos, dotados de un comportamiento intencional ${ }^{11}$. En otra perspectiva clásica, se puede también tratar de explicar la religión mediante el encuentro del individuo con el poder de su propia sociedad, irreductible al de la suma de sus miembros, y representado en un tótem ${ }^{12}$.

El problema de las teorías sobre el origen de la religión no estriba solamente en la dificultad de encontrar un factor que dé cuenta de la variedad enorme de la experiencia religiosa, y de su abigarrado despliegue multisecular. El problema más bien consiste en que toda explicación de lo religioso requiere comenzar delimitando adecuadamente cuál es el fenómeno que se pretende explicar. Aquí es donde la perspectiva fenomenológica tenía sin duda una ventaja esencial. Y es que, antes de explicar los orígenes de la religión, nos proponía comenzar con una descripción lo más detallada posible de la experiencia, tratando de detectar en ella algunos elementos esenciales, sin los cuales esa experiencia difícilmente podría ser considerada como religiosa. En concreto, lo «sagrado» sería ese elemento esencial que caracterizaría a todo lo religioso. Lo sagrado estaría caracterizado por la percepción de una majestuosidad originaria, de un misterio tremendo, que resulta a la vez aterrador y fascinante. Antes de toda teoría, incluso antes de toda teoría teológica, la religión estaría caracterizada por la vivencia de lo sagrado.

Ahora bien, esta perspectiva "hierológica» no deja de plantear algunas dificultades. De entrada se podría apuntar de nuevo que no todas las experiencias que se suelen considerar como "religiosas» se dejan integrar con la misma facilidad bajo este epígrafe de lo sagrado. Así, por ejemplo, desde una perspectiva judía se podría alegar que la sacralidad de la que nos habla Otto califica más bien la experiencia pagana de la «hechicería», y no la transcendencia radical del tres veces santo ${ }^{13}$. No solo eso. En realidad, la misma distinción entre lo sagrado y lo santo no servía originalmente para conceptuar la transcendencia del monoteísmo abrahámico, sino para señalar una dualidad originalmente indoeuropea. Lo santo designaría lo inaccesible a la acción humana, mientras

9 Cf. Feuerbach, L., Das Wesen des Christentums, Wigand, Leipzig, 1841.

10 Cf. MARX, K., «Zur Kritik der Hegelschen Rechtsphilosophie. Einleitung» en Karl MarX-Friedrich EngeLs, Werke, vol. 1, Dietz Verlag, Berlin, 1976, pp. 378-391, específicamente p. 378.

11 Cf. Bueno, G., El animal divino. Ensayo de una filosofía materialista de la religión (2a ed. corregida y aumentada), Pentalfa, Oviedo, 1996.

12 Cf. Durkheim, É., Les formes élémentaires de la vie religieuse. Le système totémique en Australie, PUF, Paris, 1990 (1 ${ }^{\mathrm{a}}$ ed. 1912).

13 Cf. Levinas, E., Difficile Liberté. Essais sur le judaïsme, A. Michel, Paris, 1976 (2 ed); Du Sacré au Saint. Cinq nouvelles lectures talmudiques, Éditions de Minuit, Paris, 1977. 
que lo sagrado sería lo que está propiamente dedicado a los dioses ${ }^{14}$. Sin duda, se puede reconocer en ambos términos una misma etimología, relacionada con el «sancionar». Sin embargo, esta diversificación originaria de los significados muestra también los límites del intento de entender lo religioso a partir de un determinado sentido, como pueda ser el de la sacralidad. ¿Qué sucede cuando ese concepto se divide en dos? ¿Cuál de los dos términos es el que ha de servir para designar el núcleo de la experiencia religiosa? ¿Son los términos para la sacralidad universalmente traducibles y equivalentes?

\section{Más allá de lo sagrado}

Ante la inevitable variabilidad histórica de los sentidos presuntamente «religiosos» se podría intentar una aproximación a la raíz de esa multiplicidad de sentido a partir de una estructura originaria, más radical que la sacralidad. De hecho, los mismos fenomenólogos de la religión, incluso cuando claramente estuvieron situados en la corriente «hierológica», no dejaron de remitir lo sagrado a unas estructuras más profundas, como sería el «misterio» o la «divinidad» ${ }^{15}$. El mismo Husserl, a pesar de sus simpatías hacia los trabajos de Otto, no utilizó la categoría de lo sagrado para entender lo más auténticamente religioso, sino que más bien apeló a la revelación de la vida divina en el sujeto individual, en contraste con toda institucionalización «sacerdotal $»^{16}$. Heidegger, por su parte, propuso entender lo sagrado a partir de la «verdad del ser», es decir, a partir del acontecimiento apropiatorio (Ereignis) por el que el ser viene a la presencia ${ }^{17}$. Zubiri, en una dirección semejante, interpretó que lo sagrado se deriva de un momento primigenio, que sería la «religación» de la persona humana al poder de lo real ${ }^{18}$.

Más que analizar estas propuestas concretas, comencemos atendiendo a su enfoque fundamental. El servicio que podrían prestarnos estos planteamientos filosóficos contemporáneos sería el de indicar alguna estructura originaria que podría considerarse como constitutiva de todo lo que entonces podría ser llamado «religión» en un sentido estricto. La religión sería precisamente la «plasmación»

14 Cf. Benveniste, É., Le vocabulaire des institutions indoeuropéennes, vol. 2, Éditions de Minuit, Paris, 1969, pp. 179-192

15 Cf. WACH, J., Religionswissenchaft. Prolegomena zu ihrer wissenschafttheoretischen Grundlegung, J. C. Hinrichs'sche Buchhandlung, Leipzig, 1924; G. van der Leeuw, Phänomenologie der Religion, J.C.B. Mohr (Paul Siebeck), Tübingen, 1933; J. Martín Velasco, Introducción a la fenomenología de la religión, Trotta, Madrid, 2006 ( $7^{\text {a }}$ ed. corregida y aumentada).

16 Cf. Husserl, E., «Fünf Aufsätze über Erneuerung», en sus Aufsätze und Vorträge (19221937), Husserliana XXVII, Martinus Nijhoff, Den Haag, 1988, pp. 3-94. Una interpretación que en cierto modo se continúa en Henry, M., C'est moi la vérité. Pour une philosophie du christianisme, Seuil, Paris, 1996.

17 Cf. Heidegger, M., Wegmarken, GA 9, Vittorio Klostermann, Frankfurt a. M., 1976, p. 351.

18 Cf. ZubiRI, X., Sobre la religión, Alianza Editorial, Madrid, 2017 
concreta de esa estructura. Con esto, no se abandona la perspectiva «descriptiva», propia de la fenomenología. Es decir, no estaríamos todavía tratando de elaborar algún tipo de teoría que pudiera explicar el origen de la religión. Todavía estaríamos tratando de describir un elemento propio de toda experiencia religiosa, que como tal sería accesible a una descripción. Y la «verificación» de esa descripción no sería otra que una «repetición» de la misma por parte de los mismos investigadores, que de este modo la irían precisando y enriqueciendo.

Ahora bien, ¿cómo se puede pretender que una estructura determinada está presente en toda experiencia religiosa? Ciertamente ya no se pretendería la universalidad de un cierto concepto con el que se pretende dar sentido a lo religioso, sino solamente la universalidad de una estructura anterior, más elemental. Es posible incluso que esa estructura fuera propia de toda experiencia humana, con lo cual podríamos tal vez entender la aparente universalidad de lo religioso. Un modo de poner a prueba este modo de enfocar la cuestión sería entonces preguntarnos si en los orígenes mismos de lo religioso se pudiera detectar la presencia de algún elemento que pudiera considerarse como característico de toda forma religiosa. De ser así, la pregunta sobre lo constitutivo de la experiencia religiosa no se limitaría al intento de comprender un pasado más o menos perdido en la noche de los tiempos, sino que serviría para determinar aquellas estructuras permanentes que caracterizarían a toda forma de religiosidad, tanto pasada como presente. De este modo, la filosofía de la religión no partiría de un concepto apriorístico de lo religioso, sino que obtendría el concepto de la religión como resultado mismo de sus investigaciones.

No se trata de una tarea fácil. ¿Cómo se puede llevar a cabo una investigación positiva sobre formas de religión perfectamente alejadas de las nuestras, de las que ni siquiera tenemos un testimonio escrito que permita intentar en algún modo su comprensión? Antes de la aparición de las grandes civilizaciones, que nos han legado algunos escritos religiosos, ¿en qué consistía la religión practicada por la mayor parte de la humanidad? Pensemos, por ejemplo, en las pinturas rupestres. Hoy en día prácticamente nadie duda de su carácter «mágico» o "religioso», por más que al mismo tiempo parezca imposible acceder al sentido con el que fue vivida tal religiosidad. No disponemos de testigos vivos, ni de textos escritos que nos puedan aclarar sobre el sentido de tales pinturas. Tampoco los "paralelos etnográficos» del presente nos pueden dar una gran seguridad, porque no podemos saber si esos presuntos paralelos son en realidad formas ya muy evolucionadas de la religiosidad más antigua, o si han sido influidos a lo largo del tiempo por otras formas religiosas.

Estas carencias tienen empero una cierta contraparte. De lo que carecemos ciertamente es del sentido concreto con el que se vivieron esas pinturas. El sentido que nosotros les podamos atribuir (por ejemplo, el sentido de "sagrado») difícilmente podría presentarse como una «traducción» literal del sentido con el que esas pinturas fueron experimentadas en el pasado. Sin embargo, hay algo de lo que sí disponemos, y que son precisamente las pinturas mismas que fueron experimentadas con unos sentidos definitivamente perdidos para 
nosotros. Estas pinturas, en su ubicación temporal y espacial concreta, fueron aquellas «cosas» que en algún momento de la prehistoria tuvieron un sentido, cualquiera que este fuera, perteneciente al ámbito de lo religioso. De ahí que, en este caso, sea posible una verdadera "repetición», no de los sentidos religiosos del pasado, sino de la aprehensión asombrada de aquello que en su momento tuvo un sentido que sospechamos «religioso».

\section{LAS PINTURAS RUPESTRES}

Ciertamente, no faltan de nuevo las «teorías» destinadas a explicar el origen de las pinturas rupestres. Debido a la alta calidad estética de algunas pinturas, hubo quienes pensaron que ellas podrían haber tenido una intención meramente artística $^{19}$. Sin embargo, la hipótesis del «arte por el arte» no explica bien por qué las pinturas se centraron en unas pocas especies animales. También fue usual alegar, frente a la idea del puro arte, la ubicación remota de las pinturas en algunas de las cuevas. Los lugares usuales de habitación estaban cercanos a la entrada de las cavernas, donde llegaba la luz del sol. En cambio, las pinturas estarían en sitios carentes de iluminación natural, con accesos más bien difíciles, e incluso en cuevas que nunca fueron habitadas. Para algunos, esto favorecía la idea de la caverna como una especie de «santuario». Ahora bien, ¿qué sentido religioso podrían tener estos «santuarios»?

A veces se pensó en que las pinturas rupestres podrían haber tenido un uso "totémico», en el sentido de Durkheim, pues podrían haber servido para representar el animal que identificaría a un determinado grupo humano. Pero esta teoría no explica bien la considerable limitación de los motivos, ni tampoco su extensión geográfica. Algunas especies, como caballos o bisontes, aparecen con muchísima frecuencia, en casi todas las cuevas, mientras que la presencia de otras especies es escasa o nula. En cambio, el totemismo exigiría una multiplicidad de los emblemas tribales a lo largo del espacio y el tiempo. Inversamente, en un mismo período y lugar no debería aparecer más que un solo emblema tribal. Sin embargo, a veces es posible reconocer, en las pinturas, la obra de un mismo artista, que si tuviera intereses totémicos, tal vez no habría representado más que un único motivo.

De ahí la hipótesis, que durante un tiempo fue generalmente aceptada, de un uso «mágico» de las representaciones pictóricas, tomando la «magia» en el sentido de Frazer $^{20}$. Los primitivos artistas habrían representado aquellos animales que pretendían cazar $^{21}$. El hecho de pintarlos les proporcionaría un poder sobre ellos, o favorecería también su reproducción, y por tanto la

19 Cf. Piette, E., L'art pendant l'Age du renne, Masson, Paris, 1907.

20 Cf. Frazer, J., The Golden Bough. A Study in Magic and Religion, Macmillan, New York, 1922 ( $1^{\text {a }}$ ed. en 2 vols. en 1890).

21 Cf. Breuil, H., Quatre cents siècles d'art pariètal, Centre d'Etudes et de Documentation Prehistoriques, Montignac, 1952. 
abundancia de presas. Esto explicaría la constante repetición de ciertas especies de animales en las pinturas, y su ubicación remota en las cuevas. La pintura no habría sido algo público o decorativo, sino parte de una ceremonia que se realizaría en lugares especiales, adonde acudirían los chamanes, los cazadores, o quienes iban a ser iniciados en la caza. Sin embargo, esta hipótesis tiene una grave dificultad. Y es que el estudio reciente de la dieta de los primitivos cazadores muestra una importante divergencia entre lo que se cazaba y lo que se pintaba. O la «magia de caza» fallaba continuamente, lo cual la haría inservible a la larga, o el propósito primario de las pinturas rupestres no era la adquisición de las especies representadas.

¿Cuál podría ser entonces el sentido de las pinturas? La hipótesis estructuralista vino a sustituir a la idea de una «magia de caza». Los animales se agruparían en dos grupos principales, que representarían el principio masculino y el femenino. Los herbívoros pequeños o medios (caballo, reno, ciervo) representarían el principio masculino, y los herbívoros grandes (bisonte, uro) representarían el principio femenino. Los signos masculinos estarían a la entrada de las cavernas, mientras que en el centro de las mismas se representaría la dualidad entre lo masculino y lo femenino. Otros animales periféricos (mamut, venado, ibex) se distribuirían en torno a estos dos grandes grupos, mientras que el grupo de los animales peligrosos (felinos, osos, rinocerontes) quedarían relegados al fondo de las cuevas. De este modo, la caverna representaría el mundo simbólico de la humanidad primitiva ${ }^{22}$. Aunque la hipótesis resulta todavía atractiva ${ }^{23}$, presenta sin embargo una importante dificultad. Y es que el descubrimiento de nuevas cuevas en las últimas décadas ha mostrado una distribución de las pinturas que difícilmente se corresponde con las predicciones de esta teoría.

En la actualidad ha ido cobrando fuerza la hipótesis que a veces se llama «chamanista». En esta perspectiva, las pinturas rupestres se habrían realizado en "estados alterados de la conciencia», en las que algunos individuos habrían tenido visiones del "otro mundo", respecto al cual las paredes de las cavernas representarían una especie de frontera. El consumo de plantas alucinógenas o la exposición a largos períodos de oscuridad habría favorecido este tipo de experiencias. Los animales representados en las paredes serían los habitantes del mundo espiritual, tal como se mostrarían a los chamanes en sus visiones. Los relieves y otros accidentes de las cuevas habrían ayudado a situar tales «apariciones» en las paredes de las cavernas, que después habrían sido fijadas de una manera permanente mediante diversos símbolos y, en el grado más elaborado, mediante las pinturas. Los negativos de algunas manos que fueron cubiertas de pintura en algunas paredes representarían precisamente ese intento de los humanos de unirse con el mundo de los espíritus ${ }^{24}$.

22 Cf. Leroi-Gourham, A., Les religions de la Préhistoire, PUF, Paris, 1964.

23 Aczel, A. D., The Cave and the Cathedral, Wiley, Hoboken, NJ, 2009.

24 Cf. Lewis-Williams, D., The Mind in the Cave, Thames \& Hudson, London, 2002. 
Por supuesto, se podrían combinar entre sí elementos de varias de las teorías mencionadas, y de otras disponibles ${ }^{25}$. Ciertos símbolos, con un origen «chamánico», podrían por ejemplo usarse en un sentido «totémico»o «mágico». O simplemente podrían usarse para unir al grupo en torno a ciertos relatos, sin que fuera esencial el componente religioso. De hecho, la separación entre las pinturas y los espacios habitados no es siempre tan clara como se pensaba. Ello cuestionaría la idea de unos «santuarios» en los que las pinturas tuvieran una función primariamente religiosa, si por tal se entiende una «relación con Dios ${ }^{26}$. Ahora bien, esta idea de lo religioso no deja de ser un anacronismo monoteísta. De hecho, la hipótesis chamánica no habla de una relación con Dios, sino de algo más elemental, que sería la manifestación del mundo espiritual en las paredes de las cavernas. En todo caso, tampoco la hipótesis chamánica es incompatible con otras teorías, pues en las «apariciones» parietales podrían estar funcionando también ciertas divisiones básicas del mundo espiritual entre lo masculino y lo femenino, etc.

No nos compete aquí juzgar sobre la mayor o menor capacidad explicativa de tales teorías, o de sus combinaciones. Sin embargo, sí es importante observar que en todas ellas se presupone una cierta idea de lo religioso. Así, por ejemplo, cuando se niega la existencia de un componente religioso, ello se debe a que se entiende la religión como un "contacto con Dios», algo que sin duda sería muy difícil de postular para los pintores parietales. Ahora bien, la negación de la religión en este sentido admite la posibilidad de que los pintores prehistóricos practicaran la magia ${ }^{27}$. Y entonces se podría pensar que la religiosidad primigenia era más bien magia, en el sentido de Frazer. En cualquier caso, seguimos presuponiendo una cierta idea de lo que sea la religión. Lo mismo sucede cuando se entiende lo religioso a partir de lo totémico, al estilo de Durkheim. O cuando se entiende lo religioso desde el ámbito de la sexualidad y de la reproducción. O cuando se piensa que lo religioso está primeramente relacionado con el mundo de los espíritus, y de los estados alterados de la conciencia en los que se accede a ellos.

En todos estos casos, las distintas hipótesis nos dicen mucho sobre las ideas de la religión que tienen los investigadores actuales, pero no es tan seguro que nos hablen necesariamente sobre las ideas religiosas de la humanidad prehistórica. Sin embargo, precisamente por la carencia de una base documental que nos permita entender el sentido prehistórico de esas pinturas, podamos preguntarnos inversamente qué es lo que esas pinturas pueden decirnos a nosotros hoy, para así plantearnos, en una dirección inversa a la teoría, cuál podría ser su sentido religioso permanente.

25 Cf. Ucko, P. y Rosenfeld, A.,Arte Paleolítico, Guadarrama, Madrid, 1967.

26 Cf. Balbín, R. y Alcolea, J. J., «Vie quotidienne et vie religieuse. Les sanctuaires dans l'art paléolithique», en L'Anthropologie 103 (1999) 23-49.

27 Cf. ibid, p. 25. 


\section{LA BELLEZA}

Más allá de todas las teorías, hay algo que podemos decir de un modo más inmediato sobre las pinturas rupestres, o al menos sobre algunas de ellas: estamos ante pinturas que son bellas. La belleza parece ser un elemento ineludible de su descripción. A Picasso se le atribuye la frase según la cual «después de Altamira, todo es decadencia». Esto no quiere decir que las pinturas fueran mero «arte por el arte», pues sus funciones y motivos pudieron ser mucho más complejos. Sin embargo, la belleza de las pinturas rupestres muestra que, con independencia de las intenciones y de los usos que pudieron tener en el mundo paleolítico, ellas fueron también verdaderas «obras de arte».

Ahora bien, ¿qué quiere decir esto? ¿Qué es el arte? Desde el punto de vista de un paleontólogo como Mithen, se podría decir que el arte designa a ciertos elementos de élite que, o bien son figurativos, o bien pertenecen a un código simbólico, como sucede cuando se repiten los mismos motivos ${ }^{28}$. Pero esto es todavía una definición demasiado amplia. Es verdad que el término «arte», en un sentido originario, engloba todo lo que hacen los «artesanos». Sin embargo, no todo lo artesanal es artístico. Posiblemente eso se debe a que nuestro concepto moderno de arte entraña una referencia a la belleza. Una letra, por ejemplo, por más que pertenezca a un código simbólico, no es necesariamente bella. Por otra parte, la belleza transciende a lo artístico. Es lo que sucede, por ejemplo, con la belleza del cuerpo humano o de un paisaje.

¿Qué es entonces la belleza? Una línea para entender la belleza podría ser la naturaleza misma. Se podría decir, por ejemplo, que «el arte imita la naturaleza». La naturaleza proporcionaría ciertas formas y estructuras, que serían un canon de lo bello para toda forma de arte. Por ello, a poco que se considere esta tesis, aparecen de nuevo algunas dificultades. El arte abstracto, por ejemplo, no imita a la naturaleza, ni reproduce necesariamente sus estructuras, y aun así lo podemos considerar como bello ${ }^{29}$. Más aún, si el arte fuera bello por ser una imitación de la naturaleza, quedaría por explicar qué tiene la naturaleza para que la podamos considerar como bella.

En este punto se podría apelar al atractivo que poseen ciertas cosas naturales que nos resultan placenteras. Sin embargo, ya los griegos observaban que no todo lo placentero es necesariamente bello. Un olor, natural o artificial, puede ser placentero, pero no lo consideramos necesariamente como bello. Lo bello parece estar más relacionado con algunos sentidos, como la vista o con el oído, y no tanto con los olores o los sabores ${ }^{30}$. Pero con ello no se aclara aún qué es lo que determina el carácter bello de lo percibido. Desde el punto de vista de la moderna neurociencia, se apela a la atracción sexual de los cuerpos, o a otros

28 Cf. Mithen, S., Arqueología de la mente. Orígenes del arte, de la religión y de la ciencia, Crítica, Barcelona, 1998, p. 167.

29 Cf. Kandinsky, V., Über das Geistige in der Kunst, Piper Verlag, München, 1912; M. Henry, Voir l'invisible. Sur Kandinsky, François Bourin, Paris, 1988.

30 Cf. Platón, Hipias mayor 287 c - 289 c. 
efectos que una obra de arte puede producir sobre nuestro cerebro: reacciones de defensa ante la violencia, sueño por la repetición de motivos, etc. De este modo, la unión de las emociones contrapuestas favorecería las obras de arte quedaran grabadas en nuestra memoria ${ }^{31}$.

Aunque estos datos pueden aclarar mucho sobre la base neurológica de la belleza, resulta claro que no siempre que se producen emociones contrapuestas estamos necesariamente ante algo bello. También un espectáculo chabacano puede producir emociones contrapuestas en nuestro cerebro, sin que ello nos permita hablar de belleza. La belleza tiene un momento de desinterés, como diría Kant, el cual transciende las emociones concretas que puedan despertar ciertas imágenes, figuras o colores. Un bodegón no es bello porque queramos comérnoslo, sino que más bien comienza a ser bello cuando no nos lo queremos comer. La belleza podría incluir algún tipo de referencia a la gratuidad, a la sobreabundancia de lo que no es estrictamente necesario. Lo que Platón llama un «alma bella», o unas «leyes bellas», podría aludir precisamente a un elemento de generosidad que va más allá de lo estrictamente necesario.

Ahora bien, ¿qué sucede cuando se habla de la belleza de la matemática, de la ciencia o de la filosofía? Aquí nos encontramos con un elemento de creatividad y de innovación que tal vez permitiría establecer alguna remota relación con la «generosidad» del alma bella. Pero se trata de asociaciones todavía muy difusas. Además, en algunos casos la actividad matemática se puede describir mejor como un "descubrimiento» que como una creación ${ }^{32}$. Por supuesto, esta impresión de "descubrimiento» no es en absoluto una "imitación de la naturaleza». La matemática puede ser bella con independencia de su posibilidad de ser aplicada para describir el mundo. Los «descubrimientos» se pueden mantener en el ámbito estricto de lo puramente postulado. Las analogías genéricas con las armonías naturales no son de mucha utilidad, pues tales analogías no acontecen siempre en el arte, y ello no obsta para que el arte pueda ser bello en grado sumo.

Algunos podrían pensar precisamente en lo contrario a una imitación de la naturaleza. El arte sería una especie de superación de la misma. El «desinterés» y la «gratuidad» del arte tendrían que ver precisamente con nuestra capacidad de independizarnos de las necesidades naturales más inmediatas. Desde el punto de vista de Max Raphael, las pinturas rupestres reflejarían la conciencia de los primitivos humanos de sobreponerse al mundo animal. ¿Por qué nos siguen pareciendo todavía bellas a nosotros? Para Raphaël se trataba simplemente de la analogía de dos momentos históricos. Así como los primitivos pintores estaban siendo conscientes de su superación del mundo animal, del mismo modo, los contemporáneos de Raphaël estarían asistiendo a la inminente superación de las fuerzas ciegas del capitalismo ${ }^{33}$.

31 Cf. Kandel, E. The Age of Insight. The Quest to Understand the Unconscious in Art, Mind, and Brain, from Vienna 1900 to the Present, Random House, New York, 2012.

32 Cf. Livio, M., Is God a Matematician?, Simon \& Schuster, New York, 2009.

33 Cf. Raphael, M., Prehistoric Cave Paintings, Pantheon, New York, 1945. 
El problema de este planteamiento consiste en que las pinturas nos siguen pareciendo bellas incluso si no nos consideramos situados históricamente en la alborada gloriosa del socialismo. En cualquier caso, Raphaël pudo haber tocado un punto importante. Y es que tal vez la belleza no haya que situarla en algunas características del mundo tomado por sí mismo, como pudieran ser las formas y armonías naturales. Pero tampoco habría que ponerla en alguna característica del ser humano, como podrían ser sus sentimientos, sus placeres, o sus neurotransmisores. Tal vez la belleza se pueda entender mejor en un momento que no pertenece al mundo ni al ser humano, sino más bien a la originaria implicación entre el ser humano y el mundo. Esto sería lo decisivo.

De hecho, la filosofía contemporánea se ha interesado particularmente por esta implicación constitutiva entre el ser humano y el mundo. La conciencia, dice la fenomenología, no es un continente abarcador de «contenidos de conciencia», sino una suerte de flecha intencional, una «conciencia-de», referida a algo otro. Para Heidegger, la intencionalidad le correspondería a la existencia humana entera, caracterizada por su radical apertura al ser ${ }^{34}$. Respecto a esta implicación entre la existencia y el ser, la obra de arte tendría una función esencial. Ella sería la que nos muestra que eso que llamamos «cosas» no son meros momentos del mundo natural, sino algo constitutivamente remitido a la existencia humana. Los zapatos de van Gogh nos remitirían a un mundo humano concreto, el mundo de la campesina, con sus luchas diarias, con sus temores y alegrías. De este modo, la obra de arte nos mostraría lo que es cada cosa: no un mero sistema de propiedades, sino algo inseparable de nuestra existencia ${ }^{35}$.

Cabe preguntarse si los zapatos, por sí mismos, remiten al mundo concreto de una campesina. Algunos estudiosos han señalado que los zapatos del famoso cuadro no eran de ninguna campesina, sino del mismo van Gogh. El mundo de esperanzas, de ilusiones, de alegrías, de temores, de angustias, etc., sería entonces totalmente distinto. Y esto, sin embargo, no cambiaría nada respecto a la belleza del cuadro. Tal vez entonces la belleza no tenga nada que ver con la concreción de la constelación de sentido al que nos parece remitir. De hecho, también un desierto deshabitado o un paisaje marciano puede ser bello, aunque esté desligado de la estructura concreta de una biografía humana. Esto nos conduce entonces a sospechar que el término de la implicación entre el ser humano y el mundo no tiene que ser necesariamente una constelación de sentido concreta, sino un momento más radical o, si se quiere, un momento «transcendental».

Desde el punto de vista de Xavier Zubiri, la «realidad» no es lo que pensó la filosofía medieval o moderna: una zona de cosas, caracterizada por estar

34 Cf. Zubiri, X., Naturaleza, historia, Dios, Alianza Editorial, Madrid, 1999 (1ª de. 1944), pp. 285-287.

35 Cf. Heidegger, M., Holzwege, GA 5, Vittorio Klostermann, Frankfurt a. M., 1977, pp. 18-22. 
«fuera de la mente». Para Zubiri, la realidad sería más bien un modo en que las cosas quedan en la aprehensión. No una zona de cosas, sino una mera «formalidad» en el sentido de un «modo de quedar» las cosas en la aprehensión. En la aprehensión, las cosas se actualizan como radicalmente otras respecto al acto mismo de su actualización. En este sentido, la realidad es un carácter transcendental de las cosas. Este primer transcendental, que es la realidad, tiene otros caracteres transcendentales, como el verum o el bonum. Aquí nos interesa el transcendental que Zubiri llama pulchrum. No sería la belleza como contrapuesta a la fealdad, sino un carácter de la realidad tal como se ofrece al sentimiento, y que permite que ulteriormente sea considerada como bella o fea, según diversos criterios estéticos, enormemente variables ${ }^{36}$. El pulchrum, como carácter de toda realidad ofrecida al sentimiento humano, sería entonces este momento transcendental de la realidad, entendida siempre como «formalidad».

Esta perspectiva, que integra la transcendentalidad de lo real en una consideración fenomenológica, puede ayudarnos a entender, por ejemplo, la belleza de un desierto, por más que el desierto no sea una obra de arte, ni forme parte necesariamente de un mundo humano: la belleza está en un momento transcendental, anterior a los sentidos concretos que le demos al desierto. Sin embargo, tal vez la idea de la belleza como mero transcendental sea algo demasiado genérico. De hecho, no todo desierto, ni todo paisaje, es necesariamente hermoso. La belleza como transcendental de la realidad es insuficiente para explicarnos por qué ciertas cosas son bellas en un sentido concreto, cuando no son feas. Al alejarnos de la belleza como transcendental de toda realidad, la distinción entre lo bello y lo feo parecería depender solamente de la variabilidad histórica de los criterios estéticos.

Ahora bien, tal vez la diversidad de los criterios estéticos no sea una pura arbitrariedad. Es posible que los múltiples criterios estéticos apunten a algo positivamente bello, a algo bello en su distinción con la fealdad. No se trata simplemente de recordar, como hacía Kant, que cuando hacemos un juicio estético estamos pretendiendo cierta universalidad. De lo que se trata es de señalar por qué en algunos casos esa universalidad se logra efectivamente. Eso es precisamente lo que tratamos de entender en estas páginas: por qué todavía hoy podemos apreciar la belleza de las pinturas rupestres, a pesar de la enorme distancia histórica y cultural, y pese a la consiguiente carencia de «cánones» culturales de belleza que podamos compartir con los primitivos pintores. Estamos ante una belleza que no es un mero transcendental, en el que las pinturas se establecerían como meras candidatas a ser bellas o feas. Lo que apreciamos en ellas es una belleza positiva, que podemos distinguir de la fealdad.

36 Cf. Zubiri, X., Sobre el sentimiento y la volición, Alianza Editorial, Madrid, 1992, p. 379 . 


\section{EL MAR DE BELLEZA}

De hecho, la alteridad radical de las cosas, su «realidad» (en el sentido de Zubiri) es un carácter propio de los actos humanos mismos. Los actos son el «surgir de las cosas» (hypárkhein tò prâgma), como ya nos decía Aristóteles ${ }^{37}$. Ciertamente se podría hablar de ellos como una «aparición», una «actualización» o una "manifestación» de las cosas. Se trata de términos usuales en la filosofía de raigambre fenomenológica. Sin embargo, al hablar de un «surgir» estamos aludiendo explícitamente a un "regir» (hypo-arkhein, sub-regere) de las cosas en alteridad radical. Con ello, no se niega el momento de alteridad radical, pero se radicaliza. Y es que, en cuanto surgir de las cosas, los actos tienen una verdad primera, anterior a la verdad propia de las cosas actualizadas en ellos. Es la verdad de la radical inmediatez de los actos. Precisamente por ser inmediatos, los actos no son «visibles», en el sentido de que los actos no se actualizan, no surgen. Precisamente son el surgir mismo de las cosas. El surgir no es una cosa, sino el conjunto de los actos humanos. A este conjunto de actos lo podemos llamar «vida» o "praxis», no en el sentido de «cosas vivas» (como las células) o de «movimientos corporales», sino en el sentido estricto de actos que, en cuanto tales, no son cosas, sino el surgir de las mismas ${ }^{38}$.

Desde este punto de vista, cabría otra comprensión de la belleza en su sentido más radical. La belleza de las cosas no consistiría primeramente en el hecho de que la realidad esté ofrecida a los actos de sentimiento. Podría suceder que el sentimiento tuviera una dimensión más originaria, que concierne a todo acto. Todo acto, en cuanto tal, está «templado» por las cosas, afectado por ellas. En este sentido, toda cosa remite afectivamente a mis actos. No se trata aquí de grados afectivos. De hecho, toda cosa, sea artificial o natural, sea parte o no de mi mundo, es algo que surge en mis actos. En todo tipo de actos, y no sólo en los actos sentimentales. En el surgir visual, auditivo, gustativo, sentimental, fantástico, reflexivo, o de cualquier otro tipo, las cosas que surgen son inseparables del surgir. Por eso son cosas. Y por eso las cosas son o pueden ser bellas, porque remiten al surgir, es decir, porque por el mero hecho de ser cosas actualizadas en nuestros actos, remiten a la vida propia de tales actos.

Podríamos entonces situar la belleza en su sentido más originario en esta primaria remisión a la vida. De hecho, tanto el término griego kalós como el alemán Held aluden justamente a la vitalidad ${ }^{39}$. Esta comprensión de la belleza nos permitiría entender, en primer lugar, su transcendentalidad. Una transcendentalidad propia de la actualización misma, y no sólo de las cosas actualizadas. Cualquier «cosa» (prâgma), aunque sea meramente pensada, lo es precisamente en su remisión al surgir en que nuestros actos consisten. Un

37 Cf. Aristóteles, Metafísica IX, 6, 1048 a 30.

38 Cf. González, A., Surgimiento. Hacia una «ontología» de la praxis, USTA Editores, Bogotá, 2012.

39 Cf. Pokorny, J., Indogermanisches Etymologisches Wörterbuch, A. Francke, BernaMúnich, 1959, vol. 1, p. 524. 
surgir que se diferencia de otro surgir por las cosas que surgen, pero no en su carácter de surgir. El surgir en cuanto tal es transcendental. Las cosas son tales en remisión al surgir mismo de todas ellas. Un surgir que es precisamente la vida originaria de los actos, el «mar de belleza» del que nos hablaba Platón ${ }^{40}$. La belleza originaria corresponde al surgir en cuanto tal.

Al mismo tiempo, la remisión de las cosas al surgir nos permite entender también que lo que surge no es siempre bello en igual medida. No todas las cosas remiten en la misma manera al surgir de las mismas. Las cosas serían tanto más bellas cuanto más trasparece en ellas la invisibilidad del surgir. El cuadro de van Gogh es bello, no por remitir a un mundo concreto, sea el del pintor o el de la presunta campesina, sino por remitir al surgir mismo de todas las cosas. Poco importa cuál sea el mundo que aparezca: lo esencial es que la pintura nos pone en la alborada sobrecogedora en que el mundo surge. Un cuadro es bello precisamente en la medida en que la contemplación de ese cuadro nos instala, no sólo ante cosas, sino en el originario surgir de todas ellas. Al mismo tiempo, podemos entender también que las cosas puedan ser feas. Lo son precisamente cuando ellas nos encierran en sí mismas, cuando se clausuran en su mera presencialidad, obturando la remisión a su constitutivo surgir.

Por supuesto, en esta perspectiva, ninguna cosa puede ser radicalmente fea, porque en toda cosa hay inexorablemente la posibilidad de acceder a la invisibilidad de su surgir. Un surgir que nunca estará dado como cosa, sino como acto. Y por supuesto también que esta remisión al surgir está condicionada por los criterios y gustos estéticos de cada época. Sin embargo, la variabilidad histórica de los criterios estéticos, de los cánones y de los gustos, se sitúa en una línea concreta, que es la línea del surgir. Los diversos criterios son variables en la medida en que son variables los modos en los que, en las cosas mismas, llega a trasparecer históricamente la invisibilidad de los actos. Los criterios variados son siempre criterios de la remisión de las cosas a la transparencia del surgir de todas ellas.

En cualquier caso, la belleza del surgir es inseparable de las cosas que surgen. Los actos son siempre el surgir de las cosas. Y esto significa entonces que, aunque los criterios de contenido, en su variabilidad histórica, son siempre secundarios, no son sin embargo prescindibles. Incluso en el arte abstracto nos encontramos, no con la pura vida, sino con «cosas» concretas, por más que estas cosas no sean representaciones de los objetos del mundo. También los puros colores, también la más aislada de las impresiones sensibles de un color, es algo que surge en nuestros actos. No hay acto de surgir sin cosas que surgen, y la belleza de lo que surge, por elemental que sea, es siempre remisión a la belleza misma del surgir.

Ahora podemos entender que haya belleza en el arte, en los saberes, y también en la naturaleza. La obra de arte, como decía Heidegger, nos remite a lo que es toda cosa. La cosa no es simplemente el ingrediente de un mundo de

\footnotetext{
40 Cf. Platón, Banquete 210 d.
} 
sentido, sino, más radicalmente, el fin o el término de un surgir. La matemática puede ser bella porque en sus creaciones acontece también la remisión al surgir de las estructuras ideales en los actos del pensamiento. Las ciencias pueden ser bellas, porque en ellas se atiende al surgir de las cosas, para entenderlo desde otras cosas que lo explican. La filosofía es bella porque siempre, en todos los tiempos, ha remitido, con menor o mayor transparencia, al surgir incansable de todas las cosas. La naturaleza en sí misma es bella, porque es precisamente eso: physis, surgir, brotar gratuito de todas las cosas. Aún así, en las cosas naturales la remisión al surgir de todas ellas acontece en formas diversas. No nos remite del mismo modo al surgir la lozanía de un cuerpo joven que la decrepitud de su vejez. Y, sin embargo, al mismo tiempo, incluso el anciano, el desierto, el paisaje marciano puede desplegar esa belleza que consiste precisamente la remisión, desde la cosa bella, al surgir de todas las cosas.

\section{LA BELLEZA RUPESTRE}

Desde este punto de vista, tal vez podemos entender mejor la belleza de las pinturas rupestres. Lewis-Williams nos hablaba de un aparecer, en las paredes, del mundo de los espíritus. Posiblemente los primeros pintores rupestres no eran platónicos como para tener una idea definida de dos mundos. Pero sí eran capaces, en cuanto humanos, de captar el surgir, y de tratar de algún modo de «fijarlo» en las paredes. Una fijación tal vez reservada para ciertos lugares de las cavernas, en los que no se pretendía alcanzar las cosas, sino el aparecer de las mismas.

El término «misterio» está ligado al myein, es decir, al «cerrar», posiblemente a los ojos que se cerraban en los cultos griegos. Con los ojos cerrados, de alguna manera nos desentendemos de las cosas que surgen, y atendemos al puro surgir. Más que una distinción entre dos ámbitos de cosas, el de este mundo y el del más allá, los primitivos pintores fueron capaces de atender a algo que pertenece a este mundo, y que sin embargo es distinto de todas las cosas. Se trata precisamente del surgir de todas ellas. El surgir no está en el más allá de otro mundo, sino en este mundo, pero en su carácter de invisibilidad.

Ahora bien, la captación del surgir acontece mediante las cosas que surgen. En este caso, la fijación pictórica del surgir se realizaba preferentemente en la representación de diversas especies animales. La razón de esta preferencia por los animales no estriba necesariamente en que tales animales fueran captados como «dioses», ni en que fueran utilizados necesariamente al servicio de una cierta «magia de caza». Lo que sucede más bien es que en los animales se capta la riqueza esplendorosa de la vida. Una vida que, como tal, no es cosa, sino distinta de todas las cosas, y sin embargo susceptible de ser percibida primariamente en su especial vitalidad ${ }^{41}$.

${ }^{41}$ Aquí cabría retomar en algún sentido las consideraciones de G. Bueno sobre los orígenes de la religión, situándolas en el ámbito más amplio del surgir. 
Al mismo tiempo, el mero hecho de pintar animales, haciendo de ellos «cosas» que surgen en los actos de representar, y en los posteriores actos visuales, muestra la incipiente conciencia de la superioridad de los actos sobre las cosas. Y, con ello, la superioridad de lo humano, a la que aludía Max Raphael. De hecho, los animales no humanos, incluyendo el resto de los primates superiores, no parecen captar los actos, sino solamente las cosas. Por eso los seres humanos pueden no sólo atender a los actos, sino también compartirlos, y de este modo ponerse en el lugar de los otros, dando lugar a las instituciones, y a un sentido de equidad. La atención a los actos marca la diferencia definitiva entre lo humano y la animalidad que permanece anclada en las cosas, y hace su vida exclusivamente en función de ellas ${ }^{42}$.

Otros aspectos de las pinturas rupestres también pueden entenderse desde aquí. La distribución de las pinturas en patrones que tal vez estén asociados con lo masculino y lo femenino podría indicar unos rudimentarios conocimientos sobre la reproducción y con ello, de nuevo, una referencia a la fecundidad y a la continuidad de la vida más allá de la finitud de los cuerpos. Es precisamente lo que también se expresa en la costumbre de enterrar a los muertos. De hecho, el uso abundante de los ocres rojos, tanto en las pinturas como en los enterramientos, puede entenderse también como la alusión a la sangre, y con ello a la vida.

En definitiva, la belleza de las pinturas rupestres nos da una clave que nos permite integrar diversas investigaciones sobre las mismas. La belleza como carácter del surgir nos mostraría que en las pinturas rupestres está envuelta una primera reflexión sobre lo originario de la vida humana. Los primitivos pintores no eran platónicos, ni siquiera eran filósofos. Sin embargo, en su experiencia, como en cualquier experiencia humana a lo largo de los tiempos, se columbra la captación de la diferencia radical entre los actos y las cosas, entre el surgir y lo que surge, y con ello el descubrimiento de lo más originario de nuestra vida, de nuestra praxis.

\section{LA RELIGIÓN ORIGINARIA}

La manifestación primaria de la belleza del surgir tal vez nos diga algo sobre lo religioso. No se trata de identificar apresuradamente lo religioso con lo bello. Sin embargo, sí podemos pensar que algo que se presenta todavía hoy como bello pudo pertenecer también al ámbito de lo religioso. No lo religioso en el sentido de un anacrónico "contacto con Dios», sino en una dimensión más elemental. Si en las pinturas rupestres había religiosidad en algún sentido, ¿Cómo era esto posible? ¿Cómo es posible que lo bello pudiera de algún modo confluir con lo religioso?

42 Cf. González, A., "Para una ontología de lo social», Revista Portuguesa de Filosofía 71/4 (2015) 833-854. 
Podríamos pensar, en primer lugar, que lo religioso atañe a la propia vida, más que a la belleza que puedan tener las cosas. Todos los análisis clásicos de lo sagrado, cuando hablaban de lo misterioso, de lo tremendo, de lo fascinante, etc., estaban en realidad hablando de la propia vida, más que de un carácter o de un sentido de las cosas. La propia vida, la propia praxis, consiste en actos. Lo misterioso, como vimos, es la propia vida, en cuanto surgir de las cosas. Lo tremendo y lo fascinante lo es en cuanto afectación de la propia vida. Cualquier observación atenta de las ceremonias (relegere) acontece en la propia vida, y como interés por ella. Somos "religiosos» en cuanto que «releemos» nuestra vida desde el punto de vista de su inserción originaria en el surgir de todas las cosas.

Y es que, si la propia vida, la propia praxis, está integrada por nuestros actos, y nuestros actos son el surgir de las cosas, resulta que lo más propio y radical de nosotros mismos está arraigado en el surgir de todas las cosas. Un acto se diferencia de otro acto en lo que surge, pero no en el surgir. En el surgir hay una comunidad originaria de acto. Más que una ligazón (religare) lo que tenemos es una primigenia comunión entre nuestros actos y el surgir de todas las cosas. Lo más íntimo de nosotros mismos no es un «sujeto» (alma, cerebro) situado más allá de nuestros actos, como soporte de los mismos. Lo más radical de nosotros mismos, lo más invisible, es algo que no es cosa, porque nunca surge como tal. Lo más radical de nosotros mismos son los actos. Y los actos propios, como surgir de las cosas, están arraigados en el infinito surgir de todas ellas. Esto es lo que, desde un punto de vista intelectual y reflexivo, se expresa hablando de Dios como más íntimo que mi propia intimidad ${ }^{43}$, o como una identidad originaria entre el atman y el brahman, tal como la proclaman las Upanishads ${ }^{44}$.

Ciertamente, ninguno de estos sentidos concretos, en sus variantes teístas o panteístas, puede ser atribuida a los primitivos pintores. La concreción de los sentidos religiosos se hunde en la distancia infranqueable de la noche de los tiempos. Pero la remisión de las pinturas a la «vida» sigue siendo patente para nosotros en el mismo día de hoy, como lo es también el anclaje de los propios actos en el surgir mismo de todas las cosas. Las cosas son bellas porque remiten al surgir, y son tanto más bellas cuanto en ellas acontece (o no) tal remisión. La religión no es la belleza de las cosas, sino la implantación de la propia vida en el surgir de todas ellas.

Éste es si se quiere, el aspecto permanente de la comprensión de las pinturas en función de las necesidades vitales de los pintores rupestres. No podía ser de otro modo. Y es que la vida humana está implantada en el surgir de las cosas, y la conciencia de esta implantación es lo que puede dar origen a las más diversas formas de religiosidad, incluyendo aquellas formas que hacen una referencia a la sacralidad. Sin embargo, toda especulación sobre lo sagrado

43 Cf. Agustín de Hipona, Confesiones III, 6, 11.

44 Cf. Chandogya Upanishad, VI, 8, 7; etc. 
queda referida a un ámbito más radical que la sacralidad, que es precisamente el misterio del surgir de todas las cosas, el «mar de belleza» en el que estamos implantados.

Desde este punto de vista, el origen de la religión no está en una religación al poder de lo real, sino la inserción en el surgir mismo de esos poderes. Ciertamente, las cosas reales tienen una poderosidad sobre la vida humana: los astros, las piedras, las aguas, las plantas, las estaciones, las plantas, los antepasados, etc., son realidades que se imponen al ser humano, y que por ello pueden ser consideradas como vehículos del poder de la realidad en cuanto tal. No cabe duda de que, en el surgir, las cosas rigen con poder en alteridad radical. Sin embargo, en esta perspectiva cabe hacer una distinción fundamental. Mientras que atendamos a las cosas que se imponen, y a la realidad de su poder, no estaremos tocando todavía la raíz más radical del misterio. El misterio compete, más que a las cosas que surgen, al surgir mismo. Y el surgir mismo no es una cosa que surge. El aparecer no aparece, la actualización no se actualiza, sino que su esencia propia es la invisibilidad. Ciertamente, yo puedo explicar las cosas que aparecen recurriendo a otras cosas. Y ahí surge la racionalidad. Pero toda explicación racional sigue siendo un acto, y como tal no pertenece a las cosas que surgen, sino al ámbito mismo del surgir.

Esta distinción está cargada de consecuencias. Atender a las cosas que surgen significa atender, no a los actos, sino a su término, a sus resultados. Atender a los resultados de los actos significa atender a las diversas realidades que "garantizan» una correspondencia entre las acciones humanas y sus resultados. Precisamente por ello el genérico poder de lo real se transforma en poderes concretos. Dicho en otros términos: el olvido de los actos entraña una atadura, una ligazón, a los poderes. Ésta es la trampa de una peculiar forma de religiosidad, que podemos llamar idolatría: el ser humano, buscando el surgir entre las cosas que surgen, queda atado, religado, no sólo a las cosas, sino también a los poderes que pretenden garantizar el surgir de las mismas. Toda interpretación totémica y chamánica de las pinturas rupestres se funda en esta dimensión secundaria de la religiosidad: ciertos lugares, ciertos símbolos, ciertas personas, se convierten en poderes, y como tales cumplen diversas funciones de orden social.

Es cierto que todo ídolo es el término de un surgir, como lo son todas las cosas. Pero en la medida en que el surgir queda definido por las cosas que surgen, el puro surgir nunca es alcanzado, y el ser humano pierde el fin (hamartía) de su propia vida, que nunca había estado fuera de ella misma, fuera de los propios actos. Es el olvido de los actos, el olvido «más feo que un pecado», como dice la expresión popular.

En la historia de las religiones aparece sin embargo otra vía. Una vía que pretende precisamente, no la religación, sino la «desligación» de todos los poderes de lo real. Es la vía abrahámica, que renuncia a la religión astral de Mesopotamia y a los rituales cruentos de Canaán. Es la vía mosaica, que rompe con la religión estatal establecida, con sus vínculos a los ciclos de las cosechas, a los templos y a los sacerdotes. Es la vía de la «desligación». O, si se quiere, la 
vía de la liberación. En esta vía, ninguna cosa, ningún lugar, ningún ídolo sirve como «re-presentación» del puro surgir de todas las cosas.

Y es que, en esta vía, el puro surgir no puede ser representado porque no es una cosa que se «pre-sente». El puro surgir no es ente, sino acontecimiento. Un acontecimiento que, como tal (ad-cum-ting-esc-ere) llega a «tocar» al ser humano, no en lo que tiene de cosa, sino en lo que tiene de acto. Un acontecimiento en el que el ser humano es entonces liberado del poder de las cosas para ser declarado, no una cosa más, sino verdadera imagen de «la divinidad». Una divinidad que no puede ser más que una, porque el surgir se diferencia del surgir solamente por lo que surge, y no en lo que tiene de puro surgir. Una divinidad entonces que rompe con todos los «lugares» sociales de lo divino, porque no es cosa, sino puro surgir infinito, surgir sin término, libre de todas las cosas. Una divinidad que entonces puede debelar toda idolatría y todo poder de lo real para invitar al ser humano al éxodo de la libertad.

En este punto de vista, la realidad entera de todas las cosas del mundo aparece ahora como término de un acto, de un acto puro, de una creación. De una creación que es bella, como expresión gratuita, sobreabundante y generosa de la belleza del puro surgir. Un surgir que, por ser puro, no surge, es insurgente, es el Insurgente, el único capaz de llamar a la radical libertad. Por ello, la vinculación al puro surgir ya no puede ser atadura, ya no puede ser arte, ni puede ser religión. Más allá de las cosas, más allá de los ídolos y de sus poderes, la vinculación con la belleza originaria no puede ser más que confianza en quien no surge, porque es el acto puro, el puro surgir.

\section{FIN}

El misterio rupestre está entonces atravesado por una radical ambigüedad. Es la ambigüedad propia de un «buscar a tientas» ${ }^{45}$, iniciado ya en la profundidad de las cavernas, y prolongado en la historia religiosa de la humanidad. Un buscar a tientas en el que se trata de encontrar, en las cosas mismas, aquello que transciende toda cosa. Un buscar que es también siempre, en alguna medida, un encontrar. Y es que, si lo que se busca es el puro surgir, resulta obvio que en ese puro surgir "nos movemos, vivimos y somos». Somos, en realidad, su propio linaje, y nunca puras cosas entre las $\operatorname{cosas}^{46}$. El puro surgir «no surge lejos de cada uno de nosotros» ${ }^{47}$.

Al mismo tiempo, la liberación de toda idolatría, de todo poder y de toda religión no puede ser definitiva más que cuando el puro surgir irrumpe entre las cosas, anulando el fundamento de todos los poderes de lo real, y cargando con el destino de aquellos que esos poderes condenan. La epifanía del puro

\footnotetext{
45 Hechos 17:27.

46 Cf. Hechos 17:28.

47 Hechos 17:27.
} 
surgir no puede ser más que la deformación de la belleza de todo ídolo, el acontecer personal de ruptura con toda gloria y con todo poder, el encuentro con aquél "ante quien se vuelve el rostro ${ }^{48}$. La palabra de la cruz inaugura, más allá de toda religión, los tiempos de refrigerio, los tiempos del Espíritu, los tiempos en los que la humanidad puede finalmente exclamar: «tarde te amé, hermosura tan antigua y tan nueva, tarde te amé» ${ }^{49}$.

Fundación Xavier Zubiri

ANTONio GonZÁLEZ

Madrid

glez.fdez.antonio@gmail.com

[Artículo aprobado para publicación en enero de 2019]

48 Cf. IsAíAs 53:3.

49 Agustín de Hipona, Confesiones X, 27, 38. 